\title{
Erratum to: Cover essay
}

\section{Joseph Piven}

Published online: 15 May 2010

(C) Springer Science+Business Media, LLC 2010

\section{Erratum to: J Neurodevelop Disord}

\section{DOI 10.1007/s11689-010-9042-7}

The original version of this article unfortunately contained a mistake. Joseph Piven, not Fredda Monroe, wrote the cover issue text of Volume 2, Issue 1 dated March 2010.

The online version of the original article can be found at http://dx.doi. org/10.1007/s11689-010-9042-7.

J. Piven $(\bowtie)$

Carolina Institute for Developmental Disabilities,

University of North Carolina,

Chapel Hill, NC 27599, USA

e-mail: joe_piven@med.unc.edu 